\title{
A novel fluorometric turn-on assay for lipase activity based on an aggregation-induced emission (AIE) luminogen
}

Jie Shi, ${ }^{a}$ Shan Zhang, ${ }^{a}$ Mingming Zheng, ${ }^{a}$ Qianchun Deng, ${ }^{a}$ Chang Zheng, Jing Li ${ }^{b}$ and Fenghong Huang ${ }^{a^{*}}$

${ }^{a}$ Oil Crops Research Institute, Chinese Academy of Agricultural Sciences, Hubei Key Laboratory of Lipid Chemistry and Nutrition, Wuhan 430062, China

${ }^{\mathrm{b}}$ Collage of Food Science and Technology, Huazhong Agricultural University, Wuhan 430072, China

*Corresponding author. Phone: 86-27-86827874; Fax: 86-27-86815916; E-mail: shij@whu.edu.cn 


\begin{abstract}
Lipase plays critical roles in the industrial catalysis, drug discovery and medical diagnosis of diseases. In this paper, based on the consideration that a tetraphenylethylene (TPE) derivative P1 with a $-\mathrm{COOC}_{6} \mathrm{H}_{13}$ group can be hydrolyzed into TPE-COOH which shows low solubility in same solutions and thus aggregation can occur easily, a novel fluorescence turn-on probe bearing aggregation-induced emission (AIE) characteristics to rapidly visualize lipase activities has been constructed with compound P1. Lipase of concentrations as low as $0.1 \mathrm{mg} \mathrm{mL}^{-1}$ can be detected and the assay range of lipase was located in $0.1-1.3 \mathrm{mg} \mathrm{mL}^{-1}$. On the other hand, the selectivity of probe $\mathbf{P 1}$, dynamic monitoring of enzymatic reaction and preliminary commercially enzyme activity screening was also summarized.
\end{abstract}

Keywords: aggregation-induced emission; lipase activity assay; tetraphenylethene; hydrolysis reaction; fluorescence "turn-on"

\title{
1. Introduction
}

With the rapid development of green and sustainable chemistry, biocatalysis has been generally employed to synthesize highly stereoselective and enantiomerically pure products.[1-5] As a key component in most extensively used biocatalysts, lipases (triacylglycerol ester hydrolase, E.C. 3.1.1.3) are versatile biocatalysts that can catalyze various types of reactions, such as esterification, interesterification, aminolysis, hydrolysis, and many important classic organic reactions under mild conditions, which produce numerous important chemicals, including pharmaceuticals, agrochemicals, flavouring compounds, biopolymers, and biodiesel.[6-10] Therefore, developing technically convenient yet effective assays for monitoring lipase activity is of critical importance both for the industrial lipases optimization and for the drug discovery and medical diagnosis of diseases. So far, very rare methods have been established for lipase activity assay. Huo and Tian developed a colorimetric probe by using Tween 20 functioned GNPs (gold nanoparticles) as a reporter.[11] J.F. Jette and E. Ziomek described a quantitative lipase assay based on the interaction of Rhodamine B with fatty acids released during the enzymatic hydrolysis of triglycerides.[12]

On the other hand, it is well known that the fluorometric assay is remarkably important owing to its unparalleled sensitivity, simplicity, rapid implementation and applicability to high-throughput screening.[13-17] Fluorophores with aggregation-induced emission (AIE) characteristics have 
recently emerged as promising materials for biosensing and imaging applications[18]. Unlike conventional fluorophores suffering from fluorescence quenching in high concentration owing to strong $\pi-\pi$ interaction, AIE luminogens such as tetraphenylethene (TPE) and its derivatives enjoy high emission efficiency when their molecules are aggregated or bind to specific analytes.[19-21] To date, a great number of AIE-based "turn-on" biosensors have been reported to target proteins, nucleic acids and glucose with superior sensitivity.[22-37] Recently, some AIE-based probes to detect specific enzymes such as Caspases, MMPs, ACE and SIRTs were reported and opened new opportunities for bioprobe design with optimized performance. [38-43] However, interestingly, there are no reports concerning its utilization in the lipase activity assay. Generally, the lipase can catalyzed hydrolysis of the ester group which was connected to a luminogen then alters the properties itself and thus leads to the variation of fluorescence. In another way, some drawbacks still exist for the reported lipase assays, in these previous work, some specific substrates and indicator assays have been used as the main screening tool, however, all of which possessed relatively complicated production process and were not conveniently synthesized and some of them suffer from needing laborious procedures for preparation. Thus, development of a simple and sensitive biosensor for lipase is essential and significant.

\section{Scheme1 is here}

Herein, we report a new fluorometric turn-on assay for lipase activity by manipulating the aggregation and deaggregation of probe P1. The whole design rationale is illustrated in Scheme 1 and explained as follows: (1) probe P1 is derived from tetraphenylethylene (TPE) with an ester group. It is well known that TPE and its derivatives show AIE (aggregation induced-emission) behavior; they are almost non-fluorescent when dissolved in organic solvent, but they become strongly emissive after aggregation. In fact, various chemo/biosensors have been disclosed based on the AIE feature; (2) because of the presence of the long alkoxy chain $-\mathrm{OC}_{6} \mathrm{H}_{13}$ group it is expected that probe $\mathbf{P 1}$ is soluble in a certain solvent, hence probe $\mathbf{P 1}$ is weakly emissive in solvent according to previous studies; (3) lipase-catalyzed cleavage of the ester group in probe P1 will induce the transformation of $\mathbf{P 1}$ into TPE- $\mathrm{COOH}$, the $-\mathrm{OC}_{6} \mathrm{H}_{13}$ unit will be cut off, which may release an insoluble TPE residue (TPE-COOH) into the solvent. Accordingly, aggregation of TPE-COOH in solvent will occur and resulting in strong emission, that is to say, turn on the fluorescence. In this way, a simple fluorescence "turn-on" assay for lipase activity can be established with probe P1, 
through this pathway, the detection of lipase activity with high sensitivity and selectivity is achieved. To our knowledge, this is the first use of AIE luminogen as fluorescence indicators to evaluate lipase activity. We believe that the research of screening lipase activity would not only broaden the spectrum of AIE luminogens-based enzyme assays but also stimulate the development of AIE-based assays for new targets.

\section{Experimental section}

\subsection{Materials}

All chemicals and reagents were commercially available and used as received without further purification. Tetrahydrofuran (THF) were dried over and distilled from K-Na alloy under an atmosphere of dry nitrogen. 4-Dimethylaminopyridine (DMAP), 4-bromobenzophenone, n-butyllithium were purchased from Aldrich. Dicyclohexylcarbodiimide (DCC), p-Toluene sulfonic acid (PTSA) monohydrate were purchased from Acros Organics. Lipases from Pseudomonas cepacia (PCL), Candida Antarctica B (CALB), Pocine pancreas (PPL), Candida rugosa (CRL), Pseudomonas fluorescens (PFL), Aspergillus niger (ANL) were all ordered from Novozymes. Caspase-3, lysozyme, pepsin, albumin from human serum (HSA), acylase, glucose oxidase, $\alpha$-amylase, trypsin and laccase were all purchased from Sigma-Aldrich. 1-(4-Bromophenyl) -1,2,2-triphenylethene (TPE-Br) was synthesized according to a previous literature.[44]

\subsection{Instrumentation}

${ }^{1} \mathrm{H}$ and ${ }^{13} \mathrm{C}$ NMR spectroscopy study was conducted with a Varian Mercury 300 spectrometer using tetramethylsilane (TMS; $\delta=0 \mathrm{ppm}$ ) as internal standard. Fluorescence spectra were performed on a Hitachi F-7000 fluorescence spectrophotometer with a Xe lamp as the excitation source. Elemental analyses were performed by a 73 CARLOERBA-1106 micro-elemental analyzer. EI-MS spectra were recorded with a Finnigan PRACE mass spectrometer. Dynamic laser scattering (DLS) measurements were performed on a commercial laser light scattering instrument (Malvern ZEN3690, Malvern Instruments) at $25^{\circ} \mathrm{C}$.

\subsection{Synthesis}

\subsubsection{Synthesis of 4-(1,2,2-Triphenylethenyl)benzoic acid (TPE-COOH).}

1-(4-Bromophenyl)-1,2,2-triphenylethene (TPE-Br) was synthesized according to a reported literature. To a solution of TPE-Br $(6.0 \mathrm{mmol}, 2.466 \mathrm{~g})$ in distilled THF $(80 \mathrm{~mL}), 5.0 \mathrm{~mL}(12.0 \mathrm{mmol})$ of n-butyllithium solution (2.4 $\mathrm{M}$ in hexane) was added dropwise under $\mathrm{N}_{2}$ at $78{ }^{\circ} \mathrm{C}$. The reaction mixture was stirred and kept at $78{ }^{\circ} \mathrm{C}$ for two hours. Excess dry ice was added in one portion followed by stirring over six hours at room temperature. The resulting solution was acidified with an 
excess amount of $1 \mathrm{M}$ hydrochloric acid and extracted with DCM three times. The organic layer was combined and dried using $\mathrm{NaSO}_{4}$. After filtration, removal of the solvent gave a crude product, which was purified by silica-gel column chromatography to obtain the desired product (1.93 g, 5.13 mmol) as a white solid. Yield: 85\%. ${ }^{1} \mathrm{H}$ NMR (300 $\left.\mathrm{MHz}, \mathrm{CDCl}_{3}\right): \delta(\mathrm{TMS}, \mathrm{ppm})$ 7.91-7.86 (d, 2H), 7.19-7.09 (m, 11H), 7.06-6.98 (m, 6H). ${ }^{13} \mathrm{C} \mathrm{NMR}\left(75 \mathrm{MHz}, \mathrm{CDCl}_{3}\right): \delta$ (TMS, ppm) 172.64, 150.11, $143.79,143.52,143.39,142.97,140.31,130.97,130.73,130.17,128.43,127.97,127.34,126.41$, $126.08,125.72$.

\subsubsection{Synthesis of compound $\mathbf{P 1}$}

To a DCM solution, TPE-COOH (1.5 mmol, $0.565 \mathrm{~g})$, DCC (2.25 mmol, $0.464 \mathrm{~g})$, DMAP (0.3 mmol, $0.036 \mathrm{~g})$, PTSA monohydrate $(0.3 \mathrm{mmol}, 0.057 \mathrm{~g})$ and 1-Hexanol (6.0 mmol, $0.445 \mathrm{~g})$ were added. The reaction mixture was stirred at room temperature for 24 hours. After solvent evaporation, the crude product was purified by silica gel chromatography to afford the target product $(0.32 \mathrm{~g}, 0.74$ mmol) as a gel-like solid. Yield: 49\%. ${ }^{1} \mathrm{H}$ NMR (300 MHz, $\left.\mathrm{CDCl}_{3}\right): \delta(\mathrm{TMS}, \mathrm{ppm}) 7.78(\mathrm{~d}, 2 \mathrm{H})$, $7.11(\mathrm{br}, 11 \mathrm{H}), 7.03-7.01(\mathrm{~m}, 6 \mathrm{H}), 4.26(\mathrm{t}, 2 \mathrm{H}), 1.72(\mathrm{t}, 2 \mathrm{H}), 1.41-1.26(\mathrm{~m}, 6 \mathrm{H}), 0.89(\mathrm{br}, 3 \mathrm{H}) .{ }^{13} \mathrm{C}$ $\operatorname{NMR}\left(75 \mathrm{MHz}, \mathrm{CDCl}_{3}\right): \delta$ (TMS, ppm) 166.53, 148.62, 143.18, 143.09, 142.28, 139.91, 131.21, $128.89,128.17,127.78,127.64,126.77,126.65,64.98,31.40,28.61,25.64,22.48,13.97 . ~ M S ~(E I)$, m/z [M]: 460.24, (calcd: 459.98). Anal. Calcd for: $\mathrm{C}_{33} \mathrm{H}_{32} \mathrm{O}_{2}: \mathrm{C}, 86.05 ; \mathrm{H}, 7.00$. Found: C, 86.29; H, 6.89.

\subsection{Preparation of the solution of $\mathbf{P} \mathbf{1}$ and lipase}

A stock solution of $\mathbf{P 1}\left(1 \times 10^{-4} \mathrm{M}\right)$ was prepared by dissolving the $\mathbf{P 1}$ solid $(0.46 \mathrm{mg})$ in hexane (10 $\mathrm{mL})$. The solution of $\mathbf{P 1}(1 \mu \mathrm{M})$ in hexane were prepared by placing $0.1 \mathrm{~mL}$ of $\mathbf{P 1}$ stock solution, then diluting the solution to $10 \mathrm{~mL}$ with hexane. For a series of commercial purchased lipase (CALB) samples solutions with concentration gradients $\left(0.1\right.$ to $\left.1.3 \mathrm{mg} \mathrm{mL}^{-1}\right)$ and other commercial lipases for preliminary screening $\left(1.0 \mathrm{mg} \mathrm{mL}^{-1}\right)$ were dissolved in $0.1 \mathrm{M}$ potassium phosphate buffer $(\mathrm{pH}=7.0)$ which were prepared by $\mathrm{K}_{2} \mathrm{HPO}_{4}$ and $\mathrm{KH}_{2} \mathrm{PO}_{4}$.

2.5. Lipase activity assay and dynamic monitoring of enzymatic hydrolysis

Different concentrations of lipase stock solutions $\left(0.1\right.$ to $\left.1.3 \mathrm{mg} \mathrm{mL}^{-1}\right) 2 \mathrm{~mL}$ were mixed with $1 \mu \mathrm{M}$ P1 solution $2 \mathrm{~mL}$ in a $10 \mathrm{~mL}$ flask and stirred at room temperature for $20 \mathrm{~min}$. Then the organic layer was taken to proceeded fluorescence measurements with an excitation wavelength of $350 \mathrm{~nm}$. The enzymatic hydrolysis process was monitored by the fluorescence spectral measurements which scanned at intervals of $120 \mathrm{~s}$. 
Scheme 2 is here.

\section{Results and Discussion}

\subsection{Design, synthesis and structural characterization of $\mathbf{P 1}$}

The design rationale is illustrated in Scheme 1. As is known to all, the hydrolysis of ester group can be carried out by lipase, hence this mode of stimuli can activate the fluorescent response through a simple reaction. The hydrolytic cleavage of the ester bond in P1 catalyzed by lipase and TPE-COOH was produced, then, the rapid aggregation of TPE-COOH in the same solution will be triggered because of its lower solubility which caused by the loose of $-\mathrm{OC}_{6} \mathrm{H}_{13}$ group.

The biosensor P1 was synthesized using the synthetic protocol described in Scheme 2 and starting from 4-bromobenzophenone and diphenyl methane leading to compound TPE-Br, which was esterificated with 1-hexanol to yield probe P1. The structure and purity of $\mathbf{P 1}$ were confirmed by ${ }^{1} \mathrm{H}$ NMR, ${ }^{13} \mathrm{C}$ NMR, EI-MS and elemental analysis.

Fig. 1 is here.

\subsection{AIE properties of TPE-COOH}

As mentioned above, we assumed that the assay of lipase activity was mainly completed by monitoring the fluorescence that attribute to the forming of TPE-COOH. Thence, the AIE properties of TPE-COOH were essential to our study. We firstly investigated the photophysical properties of TPE-COOH in the aggregated state. The fluorescent property of TPE-COOH was investigated using THF and hexane solvent mixtures (Fig. 1). TPE-COOH is almost non emissive in pure THF solution. With increasing the hexane content ranging from 0 to $60 \%$, the fluorescence intensity remains at a low level. Further addition of hexane into the mixture results in a sharp and dramatic enhancement of the fluorescence intensity. At the $95 \mathrm{vol} \%$ hexane content, the fluorescence intensity is about 49-fold higher than that in the pure THF solution, suggesting that compound TPE-COOH is AIE-active.

Fig.2 is here.

\subsection{Lipase activity assay}

Obviously, the difference in solubility and emission behaviors of probe $\mathbf{P} \mathbf{1}$ and its precursor TPE-COOH inspired us to utilize the probe for lipase activity assay. Lipase could catalyze the 
hydrolysis reaction of monoester to a hydroxyl group in high efficiency. As the enzymatic product TPE-COOH is insoluble in some poor solvent, it would form aggregates to turn on the fluorescence. Thus, P1 can work as a lipase activity reporter. To check the feasibility of this design, we investigated the fluorescence change when the probe P1 was treated with lipase-buffer solution in hexane. Hexane solution of biosensor P1 $(1.0 \mu \mathrm{M})$ was prepared for the fluorescent spectral studies and Candida Antarctica lipase B (CALB) was selected to evaluate the performance of P1. As expected, the fluorescent intensity of probe P1 $(1.0 \mu \mathrm{M})$ was much weak in the testing conditions, and nearly no photoluminescence could be seen upon excitation even in a dark room (see Fig. 2). Then, we tried to add some lipase to the diluted solution of probe P1, quickly, the blue fluorescence emission turns on after mixing with lipase-buffer solution. As shown in Fig. 2A, after addition of lipase, the fluorescence intensity of the organic phase started to increase; even at the concentration of lipase as low as $0.1 \mathrm{mg} \mathrm{mL}^{-1}$, and the intensity continued to while the concentration of lipase increased. When the concentration of lipase in the probe/lipase complex reaches $1.1 \mathrm{mg} \mathrm{mL}^{-1}$, the fluorescence intensity has increased by 17 -fold compared to the blank. Upon addition of $1.3 \mathrm{mg}$ $\mathrm{mL}^{-1}$ lipase, the fluorescence increases gradually and the intensity reaches a plateau. This confirmed our idea mentioned above: accompanying with the leakage of the alkoxy chain of the ester group linked to a TPE core in the presence of some lipase, its aggregation behavior changed to give detectable fluorescent signal in response to the analytes. Ideally, the change should be from one extreme case to another, just like in our case, from the "off" state to "on". Also, Fig. 2B illustrated fluorescence titration curve of compound P1 $(1.0 \mu \mathrm{M})$ with lipase in solution, an approximate linear correlation could be observed between the emission intensity and the concentration of lipase within the range from 0 to $1.1 \mathrm{mg} \mathrm{mL}^{-1}$. The photograph was taken from the solution of probe $\mathbf{P 1}$ itself and the probe after incubation with lipase in hexane solution under UV illumination at $365 \mathrm{~nm}$. It is obvious that blue fluorescence is turned on after being treated with lipase, so significant difference in fluorescence emission was observed, and it could be easily distinguished by the naked eye under UV light, directly.

Fig.3 is here.

According to the calibration curve (Fig. 3), the relative fluorescence intensity change ratio $\left(\mathrm{I} / \mathrm{I}_{0}\right)$ at $420 \mathrm{~nm}$ also presents a linear increase with the concentration of lipase in the range from 0 to $1.1 \mathrm{mg}$ $\mathrm{mL}^{-1}\left(\mathrm{R}^{2}=0.9915\right)$, which was consistent with the variation of the fluorescence intensity. Furthermore, 
to check the reproducibility of the probing behavior, we repeated the above experiments for three times, and the testing results were also shown in Fig. 3. It was easily seen that the error bars were not big and the reproducibility was relatively good.

Fig.4 is here.

To further verify the formation of aggregates of probe P1 with lipase, particle sizes were carried out by the DLS (Dynamic Laser Scattering) analysis, and the results were displayed in Fig. 4. In the stock solution of probe P1 $(1 \mu \mathrm{M})$ with nothing added, the nanoparticles could be observed in the range of 20-100 nm, while the mean diameter of P1 is approximately $300 \mathrm{~nm}$ after treated with lipase and the maximum diameter was even up to $1 \mu \mathrm{m}$, which revealed that aggregates are indeed present in the solution. The results suggested that after incubation with lipase, the P1 was hydrolyzed to the precursor TPE-COOH, due to its insolubility in hexane solution, resulting in the formation of large aggregates, which was consistent with the fluorescence spectra. It suggested that the aggregation size significantly influenced the fluorescence of the solution, because the AIE effect could be triggered by the larger aggregates.

Fig.5 is here.

To examine the possibility of quantitative analysis of lipase activity, we conducted the experiment of dynamic monitoring of enzymatic reaction. Fig. 5 displays the variation of the fluorescence intensity at $420 \mathrm{~nm}$ of probe $\mathbf{P 1}(1 \mu \mathrm{M})$ after incubation with different amounts of lipase $\left(0-1.3 \mathrm{mg} \mathrm{mL}^{-1}\right)$ for different times at room temperature. Obviously, the fluorescence intensity increased gradually by prolonging the incubation time, with different concentrations of lipase incubated, the intensity of the probe increases gradually with different magnitudes. The fluorescence changes more obviously at the beginning for all lipase concentrations but becomes slower in the later period. The fluorescence intensity reaches the plateau after about $14 \mathrm{~min}$, indicating that probe $\mathbf{P 1}$ is nearly completely hydrolysed by lipase and the test could be completed within 14 minutes, which was much faster than traditional turbidimetric assays. Moreover, the fluorescence intensity was enhanced more rapidly when the concentration of lipase was higher. This is understandable by considering the fact that the hydrolysis of probe $\mathbf{P 1}$ would be facilitated in the presence of a high concentration of lipase. As depicted in Fig. 5, such a fluorescence enhancement was still detectable even when the concentration 
of lipase was as low as $0.2 \mathrm{mg} \mathrm{mL}^{-1}$ within 5 minutes. These results reveal that the lipase turn-on mode could be applied potentially for the real-time activity assay of lipase. Furthermore, to address the selectivity of probe $\mathbf{P 1}$, the selectivity of this fluorometric commercial assay for lipase was also tested, a control experiment with other nonspecific enzymes including caspase-3, lysozyme, pepsin, HSA, acylase, glucose oxidase, $\alpha$-amylase, trypsin and laccase was performed with a fixed concentration $\left(1.0 \mathrm{mg} \mathrm{mL}^{-1}\right)$. As shown in Fig. 6, the results revealed that about 15 -fold fluorescence enhancement of the probe was recorded with the effect of lipase, while negligible changes in emission intensity were observed for other enzymes. Thus, interferences from other enzymes can be neglected and the probe $\mathbf{P 1}$ is highly specific to lipase. To further demonstrate that fluorescence enhancement was due to lipase-catalyzed hydrolysis rather than other effects, a control experiment between lipase and inactivated lipase was conducted. Herein, lipase was deactivated in high temperature $\left(100{ }^{\circ} \mathrm{C}\right)$ and it is well known that high temperature is one of the traditional protein denaturants. According to our proposed mechanism, inactivated lipase could not hydrolyze the probe P1 and no fluorescence enhancement is expected. The fluorescence result in Fig.7 shows that inactivated lipase is not able to turn on the fluorescence, which reveals that it is the catalysis effect of lipase that functions on this process, excluding other interference effects such as hydrophobic interaction and electrostatic interaction between proteins and probes.

Fig.6 is here.

Fig.7 is here.

A preliminary screening was carried out using this system to test the activities of six commercial purchased lipase samples (CRL, PPL, RFL, ANL, CALB, and PCL). The fluorescence intensity and the $\mathrm{I} / \mathrm{I}_{0}$ value of probe $\mathbf{P 1}$ solution in the presence of a fixed concentration $\left(1.0 \mathrm{mg} \mathrm{mL}^{-1}\right)$ of lipase samples were monitored, respectively, within a fixed time interval. As shown in Fig. 8, probe P1 incubated with CALB, PPL, and ANL led to significant fluorescence changes, whereas with RFL, PCL and CRL no obvious fluorescence changes were observed. Moreover, the different fluorescence changes (strong emission in CALB, PPL, and ANL and weak emission in PFL, PCL and CRL) were attributed to the different lipase activities. With fluorescence spectroscopy quantitative detection, we conclude that the lipase activity decreases in the following order: CALB > ANL > PPL > CRL > RFL > PCL. This order is consistent with the results detected with a pH-stat method,[11] 
demonstrating the possibility that the fluorometric turn-on assay protocol can be used as an alternative to conventional methods for a sensitive assay of lipase activity. The inserted photograph in Fig. 8 was taken from the probe $\mathbf{P 1}$ after incubation with different commercial lipase in hexane solution under UV illumination at $365 \mathrm{~nm}$. It is obvious that different blue fluorescence emission related to the activity of lipases, it could be easily distinguished by the naked eye under UV light.

Fig.8 is here.

\section{Conclusions}

In conclusion, a fluorescence "turn-on" probe $\mathbf{P 1}$ for lipase activity assay was established by making use of the AIE technology. The obtained results demonstrated that: 1) the high sensitivity of probe P1, coupled with its simple structure and easy preparation, and not require specific instrumentation or complicated experimental steps, would surely contribute to its practical applications in different fields. 2) Lipase of concentrations as low as $0.1 \mathrm{mg} \mathrm{mL}^{-1}$ can be detected and the assay range of lipase was located in $0.1-1.3 \mathrm{mg} \mathrm{mL}^{-1}$. DLS studies confirmed the formation of aggregates and accordingly lipase-catalyzed hydrolysis of the fluorescent probe led to self-aggregation of insoluble products, resulting in strong fluorescence. The fluorescence "turn-on" method provided a platform for the research on lipase activity assay and other probes, including those of "on-off", are still under way in our laboratory.

\section{Acknowledgements}

We are grateful to the National Science Foundation of China (no. 31501423), the Director Fund of Oil Crops Research Institute of CAAS-Program of Young Talents (no. 1610172015006) and Agricultural Science and Technology Innovation Project of Chinese Academy of Agricultural Sciences (CAAS-ASTIP-2013-OCRI) for financial support.

\section{References}

[1] G. Yang, J. Wu, G. Xu, L. Yang, Comparative study of properties of immobilized lipase onto glutaraldehyde-activated aminosilica gel via different methods, Colloid Surf. B 78(2010) $351-356$.

[2] X. Lu, Z. Luo, S. Yu, X. Fu, Lipase-catalyzed synthesis of starch palmitate in mixed ionic liquids, J. Agric. Food. Chem. 60(2012) 9273-9279.

[3] S. Shah, M. N. Gupta, Lipase catalyzed preparation of biodiesel from jatropha oil in a solvent free system. Process Biochem. 42(2007) 409-414. 
[4] R. Gupta, N. Gupta, P. Rathi, Bacterial lipases: an overview of production, purification and biochemical properties, Appl. Microbiol. Biotechnol. 64(2004) 763-781.

[5] A. Bajaj, P. Lohan, P. N. Jha, R. Mehrotra, Biodiesel production through lipase catalyzed transesterification: an overview, J. Mol. Catal. B-Enzym. 62(2010) 9-14.

[6] C. H. Lee, T. S. Lin and C. Y. Mou, Mesoporous materials for encapsulating enzymes, Nano Today 4(2009), 165- 179.

[7] M. Kalantari, M. Kazemeini, F. Tabandeh, A. Arpanaei, Lipase immobilisation on magnetic silica nanocomposite particles: effects of the silica structure on properties of the immobilised enzyme, J. Mater. Chem. 22(2012) 8385-8393.

[8] R. D. Schmid, R. Verger, Lipases: Interfacial enzymes with attractive applications, Angew. Chem., Int. Ed. 37(1998) 1608-1633.

[9] M. Held, A. Schmid, J. B. van Beilen, B. Witholt, Biocatalysis. Biological systems for the production of chemicals, Pure Appl. Chem. 72(2000) 1337-1343.

[10]Z. Chen, W. Xu,L. Jin, J. Zha, T. Tao, Y. Lin, Z. Wang, Synthesis of amine-functionalized $\mathrm{Fe}_{3} \mathrm{O}_{4} @ \mathrm{C}$ nanoparticles for lipase immobilization, J. Mater. Chem. A 2(2014) 18339-18344.

[11]W. Zhang, Y. Tang, J. Liu, L. Jiang, W. Huang, F. Huo, D. Tian, Colorimetric assay for heterogeneous-catalyzed lipase activity: enzyme-regulated gold nanoparticle aggregation, J. Agric. Food Chem. 63(2015) 39-42.

[12]J. F. Jette, E. Ziomek, Determination of lipase activity by a rhodamine-triglyceride-agarose assay. Anal. Biochem. 219(1994) 256-260.

[13]X. J. Zhu, C. Q. Jiang, 8-Quinolyl phosphate as a substrate for the fluorimetric determination of alkaline phosphatase, Clin. Chim. Acta. 150(2007) 150-153.

[14]Y. Liu, K. S. Schanze, Conjugated polyelectrolyte-based real-time fluorescence assay for alkaline phosphatase with pyrophosphate as substrate, Anal. Chem. 80(2008) 8605-8612.

[15]S. M. Borisov, O. S. Wolfbeis, Optical biosensors, Chem. Rev. 108(2008), 423-461.

[16]J. Shi, Q. Li, X. Zhang, M. Peng, J. Qin, Z. Li, Simple triphenylamine-based luminophore as a hypochlorite chemosensor, Sen. Actuator B-Chem. (145)2010 583-587.

[17]Z. Zhu, L. Xu, X. Zhou, J. Qin, C. Yang, Designing label-free DNA sequences toachieve controllable turn-off/on fluorescence response for $\mathrm{Hg}^{2+}$ detection, Chem. Commun. 47(2011) 8010-8012.

[18]X. Zhang, X. Zhang, L. Tao, Z. Chi, J. Xu, Y. Wei, Aggregation induced emission-based fluorescent nanoparticles: fabrication methodologies and biomedical applications, J. Mater. 
Chem. B 2(2014) 4398-4414.

[19]J. Mei, N.L.C. Leung, R.T.K. Kwok, J.W.Y. Lam, B.Z. Tang, Aggregation-induced emission: together we shine, united we soar!, Chem. Rev. 115(2015) 11718-11940

[20] Y. Hong, J.W.Y. Lam, B. Z. Tang, Aggregation-induced emission: phenomenon, mechanism and applications, Chem. Commun. 45(2009) 4332-4353.

[21] Y.N. Hong, J.Y. Lam, B.Z. Tang, Aggregation-induced emission, Chem. Soc. Rev. 40 (2011) $5361-5388$.

[22]X. Gu, G. Zhang, Z. Wang, W. Liu, L. Xiao, D. Zhang, A new fluorometric turn-on assay for alkaline phosphatase and inhibitor screening based on aggregation and deaggregation of tetraphenylethylene molecules, Analyst 138(2013) 2427-2431.

[23]T. Simon, M. Shellaiah, V. Srinivasadesikan, C. C. Lin, F. H. Ko, K. W. Sun, M. C. Lin, A simple pyrene based AIEE active schiff base probe for selective naked eye and fluoresence off-on detection of trivalent cations with live cell application, Sen. Actuator B-Chem. 231 (2016) $18-29$.

[24]Y. D. Hang, X.P. He, L. Yang, J.L. Hua, Probing sugar-lectin recognitions in the near-infrared region using glyco-diketopyrrolopyrrole with aggregation induced-emission, Biosens. Bioelectron. 65 (2015) 420-426.

[25]K. Ma, H. Wang, H. Li, S. Wang, X. Li, B. Xu, W. Tian, A label-free aptasensor for turn-on fluorescent detection of ATP based on AIE-active probe and water-soluble carbon nanotubes, Sen. Actuator B-Chem. 230 (2016) 556-558.

[26]Y. Sun, Y. Li, X. Ma, L. Duan, A turn-on fluorescent probe for cyanide based on aggregation of terthienyl and its application for bioimaging, Sen. Actuator B-Chem. 224 (2016) 648-653.

[27]L. Wang, L. Yang, D. Cao, Probes based on diketopyrrolopyrrole and anthracenone conjugates with aggregation-induced emission characteristics for $\mathrm{pH}$ and BSA sensing, Sen. Actuator B-Chem 221 (2015) 155-166.

[28]R. R. Hu, N.C. Leung, B. Z. Tang, AIE macromolecules: syntheses, structures and functionalities, Chem. Soc. Rev. 43 (2014) 4494-4562.

[29]J. Shi, Y. Wu, B. Tong, J. Zhi, Y. Dong, Tunable fluorescence upon aggregation: Photophysical properties of cationic conjugated polyelectrolytes containing AIE and ACQ unitsand their use in the dual-channel quantification of heparin, Sen. Actuator B-Chem 197 (2014) 334-341.

[30]L. Y. Wang, L. L. Yang, D. R. Cao, Application of aggregation-induced emission (AIE) systems in sensing and bioimaging, Curr. Org. Chem. 18 (2014) 1028-1049. 
[31]Q. Chen, N. Bian, C. Cao, X. L. Qiu, A. D. Qi, B. H. Han, Glucosamine hydrochloride functionalized tetraphenylethylene: A novel fluorescent probe for alkaline phosphatase based on the aggregation-induced emission, Chem. Commun. 46(2010) 4067-4069.

[32]D. Ding, K. Li, B. Liu, B.Z. Tang, Bioprobes based on AIE fluorogens, Acc. Chem. Res. 46 (2013) 2441-2453.

[33]X. Xu, J. Huang, J. Li, J. Yan, J. Qin, Z. Li, A graphene oxide-based AIE biosensor with high selectivity toward bovine serum albumin, Chem. Comm. 47(2011) 12385-12387.

[34]Z. Song, Y. Hong, R. T. K. Kwok, J. W. Y. Lam, B. Liu, B. Z. Tang, A dual-mode fluorescence "turn-on" biosensor based on an aggregation-induced emission luminogen, J. Mater. Chem. B $2(2014) 1717-1723$.

[35]W. Lu, P. Xiao, J. Gu, J. Zhang, Y. Huang, Q. Huang, T. Chen, Aggregation-induced emission of tetraphenylethylene-modified polyethyleneimine for highly selective CO2 detection, Sen. Actuator B-Chem 228 (2016) 551-556.

[36]Q. Zhao, S. Zhang, Y. Liu, J. Mei, S. Chen, P. Lu, A. Qin, Y. Ma, J. Z. Sun, B. Z. Tang, Tetraphenylethenyl-modified perylene bisimide: aggregation-induced red emission, electrochemical properties and ordered microstructures, J. Mater. Chem. 22 (2012) 7387-7394;

[37]J. Mei, Y. N. Hong, J. Y. Lam, A. Qin, Y. H. Tang, B. Z. Tang, Aggregation-induced emission: the whole is more brilliant than the parts, Adv. Mater. 26 (2014) 5429-5479.

[38]H. Wang, Y. Huang,X. Zhao, W. Gong, Y. Wang, Y. Cheng, novel aggregation-induced emission based fluorescent probe for an angiotensin converting enzyme (ACE) assay and inhibitor screening, Chem. Commun. 50 (2014) 15075-15078.

[39]Y. Yuan, R. T. K. Kwok, B. Z. Tang, B. Liu, Targeted theranostic platinum(IV) prodrug with a built-in aggregation-induced emission light-up apoptosis sensor for noninvasive early evaluation of its therapeutic responses in situ, J. Am. Chem. Soc. 136 (2014) 2546-2554.

[40]J. Liang, H. Shi, R. T. K. Kwok, M. Gao, Y. Yuan, W. Zhang, B. Z. Tang, B. Liu, Distinct optical and kinetic responses from $\mathrm{E} / \mathrm{Z}$ isomers of caspase probes with aggregationinduced emission characteristics, J. Mater. Chem. B 2 (2014) 4363-4370.

[41]C. Yu, Y. Wu, F. Zeng, X. Li, J. Shi, S. Wu, Hyperbranched polyester-based fluorescent probe for histone deacetylase via aggregation-induced emission, Biomacromolecules 14 (2013) 4507-4514.

[42]K. Dhara, Y. Hori, R. Baba, K. Kikuchi, A fluorescent probe for detection of histone deacetylase activity based on aggregation-induced emission, Chem. Commun. 48 (2012) 11534-11536. 
[43]K. Han, S. Wang, Q. Lei, J.i Zhu, X. Z. Zhang,Ratiometric biosensor for aggregation-induced emission-guided precise photodynamic therapy, 9 (2015) 10268-10277.

[44]W. B. Zhou, H. Li, Z. Chi, X. Zhang, J. Zhang, B. Xu, Y. Zhang, S. Liu, J. Xu, Piezofluorochromism and morphology of a new aggregation-induced emission compound derived from tetraphenylethylene and carbazole, New J. Chem. 36(2012) 685-693. 


\section{Legend of Figures}

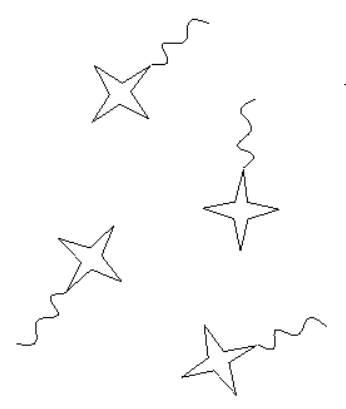

Soluble

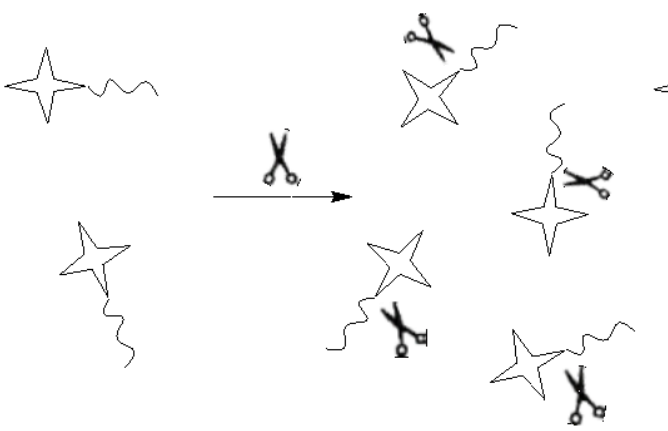

$\{\sim$ : P1 $\{:$ TPE-соOH
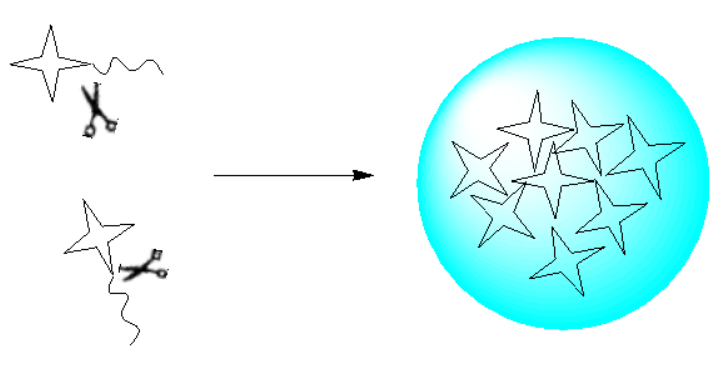

Aggregation

Scheme 1. Schematic illustration of sensing mechanisms of probe $\mathbf{P 1}$ in lipase activity assay.<smiles>Brc1ccc(C(=C(c2ccccc2)c2ccccc2)c2ccccc2)cc1</smiles>

TPE-Br

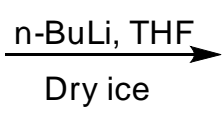

Dry ice<smiles>c1ccc(C(=C(c2ccccc2)c2ccccc2)c2ccccc2)cc1</smiles>

TPE-COOH<smiles>O=C(O[Ga])c1ccc(C(=C(c2ccccc2)c2ccccc2)c2ccccc2)cc1</smiles>

P1

Scheme 2. Synthesis route to probe $\mathbf{P 1}$.
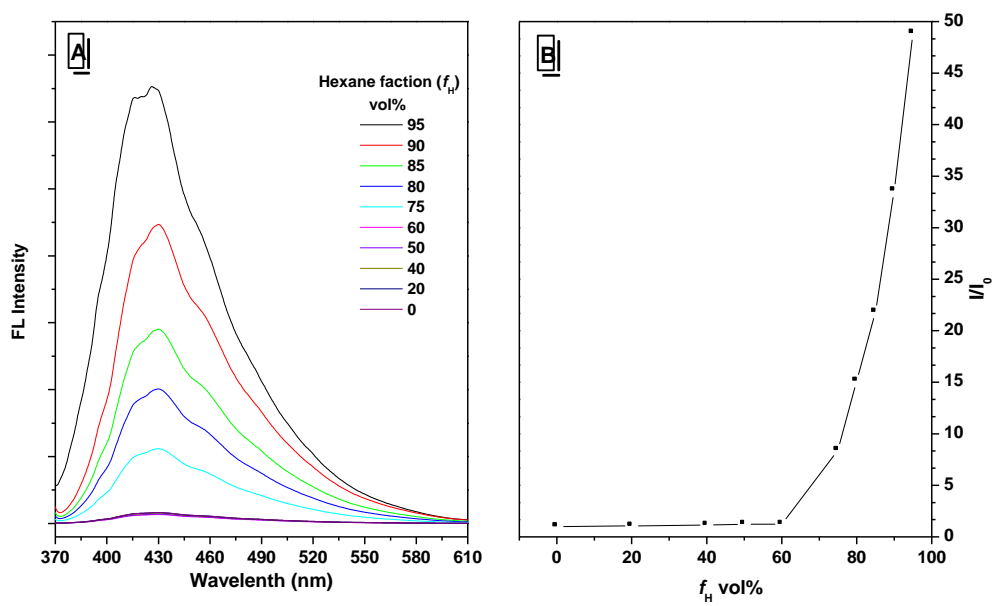

Fig. 1 (A) fluorescence spectra of TPE-COOH $(1 \mu \mathrm{M})$ in THF-hexane mixtures with different fractions of hexane $\left(f_{\mathrm{H}}\right)$. (B) Plot of $\mathrm{I} / \mathrm{I}_{0}$ at $425 \mathrm{~nm}$ versus $f_{\mathrm{H}}$, where $\mathrm{I}_{0}$ is the fluorescence intensity in pure THF solution. Excitation wavelength: $350 \mathrm{~nm}$. 

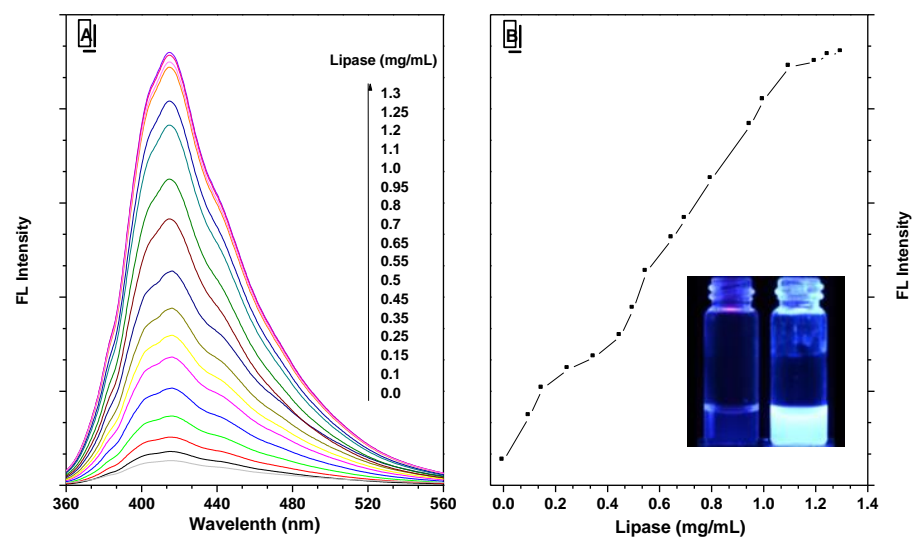

Fig. 2 The fluorescence spectra of probe $\mathbf{P 1}(1.0 \mu \mathrm{M})$ after incubation with different concentrations of lipase-buffer $\left(0.1 \mathrm{M}\right.$ potassium phosphate) solution at $25{ }^{\circ} \mathrm{C}$; inset shows the photo of the corresponding solutions of probe P1 $(1.0 \mu \mathrm{M})$ without (left) and with (right) lipase $\left(1.3 \mathrm{mg} \mathrm{mL} \mathrm{mL}^{-1}\right)$ after incubation at $25{ }^{\circ} \mathrm{C}$ for $20 \mathrm{~min}$ under UV light $(365 \mathrm{~nm})$ illumination. Excitation wavelength: $350 \mathrm{~nm}$.

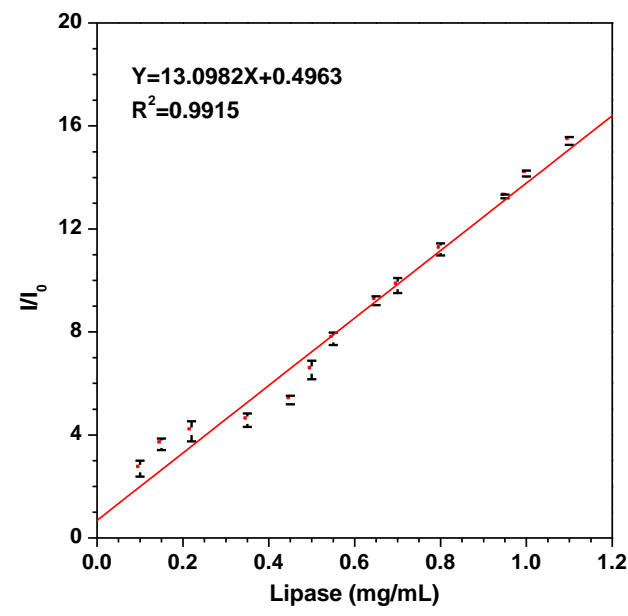

Fig. 3 Plot of $\mathrm{I} / \mathrm{I}_{0}$ and expanded linear region versus the different concentration $\left(0.1-1.1 \mathrm{mg} \mathrm{mL}^{-1}\right)$ of lipase, where $\mathrm{I}$ and $\mathrm{I}_{0}$ are the fluorescence intensities in the presence or absence of analytes. Excitation wavelength: $350 \mathrm{~nm}$. 

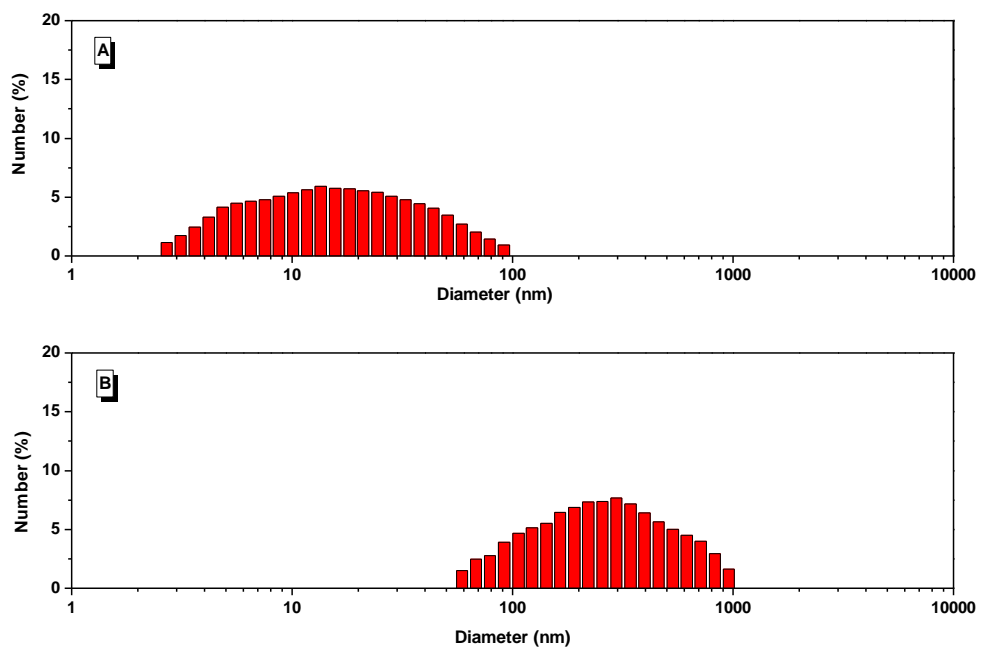

Fig. 4 Dynamic light scattering (DLS) results for the solution of probe $\mathbf{P 1}$ in the absence and presence of lipase: (a) probe P1 $(1.0 \mu \mathrm{M})$ in hexane solution; (b) probe P1 $(1.0 \mu \mathrm{M})$ in hexane solution after incubated with lipase $\left(1.0 \mathrm{mg} \mathrm{mL}^{-1}\right)$ for $20 \mathrm{~min}$.

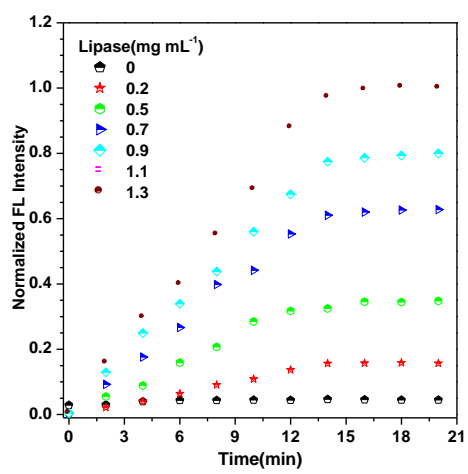

Fig. 5 Time-dependent fluorescence intensity of probe P1 $(1.0 \mu \mathrm{M})$ in hexane solution at $420 \mathrm{~nm}$ versus the hydrolysis reaction time in the presence of different concentrations of lipase at $25{ }^{\circ} \mathrm{C}$. Excitation wavelength: $350 \mathrm{~nm}$.

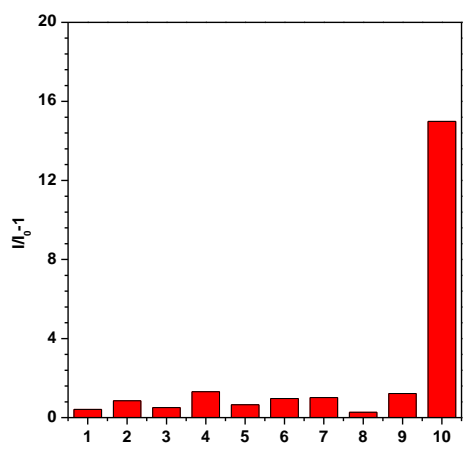

Fig. 6 Variation of the fluorescence intensity of probe P1 $(1.0 \mu \mathrm{M})$ in hexane solution at $420 \mathrm{~nm}$ after treated by 1) caspase-3, 2) lysozyme, 3) pepsin, 4) HSA, 5) acylase, 6) glucose oxidase, 7) $\alpha$-amylase, 8) trypsin, 9) laccase, 10) lipase was performed with a fixed concentration $\left(1.0 \mathrm{mg} \mathrm{mL}^{-1}\right)$. 
Excitation wavelength: $350 \mathrm{~nm}$.

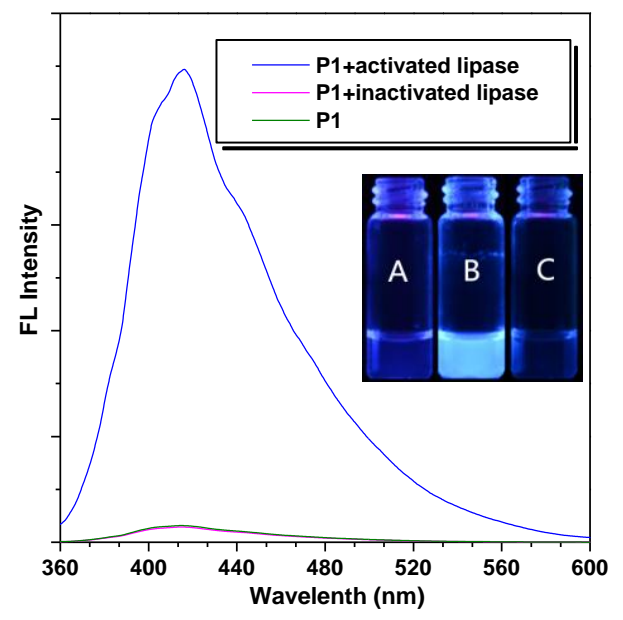

Fig. 7 Fluorescence spectra of the probe P1, probe P1/activited lipase and probe P1/inactivited lipase. Concentration: probe $\mathbf{P 1}(1.0 \mu \mathrm{M})$; activited lipase $\left(1.0 \mathrm{mg} \mathrm{mL}^{-1}\right)$; inactivited lipase $\left(1.0 \mathrm{mg} \mathrm{mL}^{-1}\right)$; Excitation wavelength: $350 \mathrm{~nm}$. Inset: photographs of corresponding solutions (a) probe P1 only, (b) probe P1/activited lipase and (c) probe P1/inactivited lipase under UV light illumination at $365 \mathrm{~nm}$.

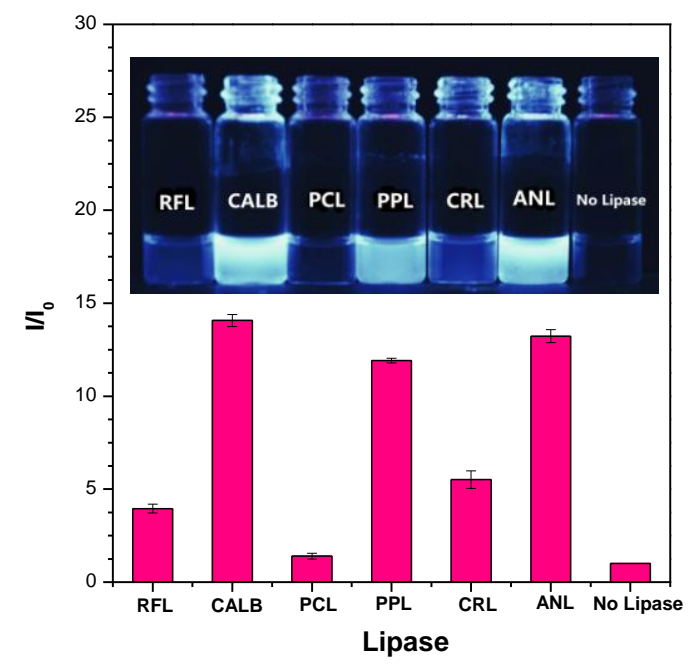

Fig. 8 Plot of $\mathrm{I} / \mathrm{I}_{0}$ intensity of probe $\mathbf{P 1}$ upon the addition of a fixed concentration $\left(1 \mathrm{mg} \mathrm{mL} \mathrm{m}^{-1}\right)$ of commercial lipase samples, respectively, and within a interval of $20 \mathrm{~min}$. (Inset) Corresponding visual fluorescence under UV light illumination at $365 \mathrm{~nm}$. 